EESTI NSV TEADUSTE AKADEEMIA TOIMETISED. 22, KOIDE KEEMIA * GEOLOOGIA. 1973, NR. 3

ИЗВЕСТИЯ АКАДЕМИИ НАУК ЭСТОНСКОИ ССР. ТОМ 22 ХИМИЯ * ГЕОЛОГИЯ. 1973, № 3

\author{
АННА ЛИННИК, УУВЕ КИРСО, Л. САВЛУЧИНСКАЯ, \\ М. ГУБЕРГРИЦ, Л. ШАБАД
}

\title{
ВЛИЯНИЕ ФЕНОЛА И 5-МЕТИЛРЕЗОРЦИНА НА КАНЦЕРОГЕННОЕ ВОЗДЕЙСТВИЕ БЕНЗ(а)ПИРЕНА
}

Фенолы - широко распространенные спутники канцерогенных полициклических углеводородов (ПАУ) в составе технических загрязнений среды. При этом самостоятельно они обладают выраженной физиологической активностью и являются сильными антиокислителями. Отличительным же признаком канцерогенных веществ любых классов является их способность к участию в окислительно-восстановительных процес$\operatorname{cax}\left[{ }^{1-3}\right]$. Изложенные обстоятельства побуждают исследователей к установлению особенностей и закономерностей сопряженного воздействия на живой организм «классических» канцерогенов, каким является, например, бенз(а)пирен (БП), и различных антиокислителей, в частности фенолов.

Предварительно укажем, что, по некоторым данным литературы, фенолы обладают антиканцерогенным действием [ $\left.{ }^{4-6}\right]$; по мнению же ряда других исследователей $\left[{ }^{7,8}\right]$, они оказываются сильными промоторами или инициаторами канцерогенеза. Сошлемся также на ряд работ $\left[^{5,9-12}\right]$, согласно которым направленность воздействия антиокислителей в биологической системе определяется как величиной их дозы, так и стадией суммарного процесса, когда они вводятся в организм и воздействуют на антиокислительную активность липидов в ходе канцерогенеза.

При всех условиях ясно, что структура фенола, вводимого в биологическую систему последовательно или одновременно с ПАУ, должна играть существенную роль в таком солряженном воздействии. Поэтому в настоящем исследовании рассматривается влияние на канщерогенное воздействие БП двух фенолов разного строения, обладающих различной реакционной способностью в процессах окисления или антиокислительной активностью - собственно фенола (Ф) и 5-метилрезорцина (МР).

\section{Объекты и методика исследования}

В эксперименте использованы БП (фирма «Fluka AG, Buchs SG»), фенол марки «ч», подвергнутый нами дополнительной очистке, и MP (фирма «Merck AG»). Оба названных фенола являются типичными представителями этого класса соединений в составе продуктов переработки сланцев и других твердых топлив наряду с БП. В качестве растворителя использован дополнительно очищенный ацетон. Растворы фенолов подготовлены с неизменной молярной концентрацией $2 \cdot 10^{-2}$ моль/л (для $\Phi-2 м 2 / \Omega$, для $M P-3 м 2 / \Omega)$, в десять раз превышающей концентрацию БП, равную $2 \cdot 10^{-3}$ моль/л или 500 мкг/л. Такое соотношение в известной мере отвечает показателям для реальных смесей. 
Опыты проведены на 213 мышах-пибридах $\mathrm{F}_{1}$ (C57 B1 × CBA), самцах и самках поровну, в возрасте от 1,5 до 2 месяцев. Животные были распределены на десять групп. Опыты состояли из трех серий (табл. 1): I - раздельная аппликация изучаемых веществ, II - совместная аппликация веществ и III - последовательная аппликация веществ, первоначально накапывание БП, а затем Ф или МР.

B I и II сериях обработку животных проводили в течение 4 месяцев дважды в неделю. Раствор наносили на депилированную кожу в межлопаточной области. В III серии, при последовательном нанесении, животных обрабатывали один месяц БП, а затем 3 месяца Ф или МР. Таким образом, во всех сериях обработку животных проводили 4 месяца и суммарная доза фенолов была одинаковой. Для БП суммарная доза составила 200 и 435 мке, для $\Phi-5,8$ мг и для MP $-7,8$ мг на каждое животное.

После окончания обработки животные находились под наблюдением еще 14 месяцев. Через полтора года от начала опыта опухоли всех животных - как погибших во время эксперимента, так и выживших, но умерщвленных, были взяты для микроскопического исследования.

\section{Результаты исследования и их обсуждение}

Результаты эксперимента сведены в табл. 1 и проиллюстрированы на рисунке. Как и следовало ожидать, количество опухолей, вызванных БП (см. контроль в табл. 2), возрастает со временем и увеличением его суммарной дозы. МР самостоятельно не вызывает злокачественных образований, а в опытах под воздействием собственно Ф возникла лишь одна опухоль, причем доброкачественная, через сравнительно длительный промежуток времени (серия I).

При совместной аппликации (серия II) оба фенола оказали тормозящее влияние на процесс канцерогенеза, обусловленный воздействием БП. Это особенно заметно при меньшей суммарной дозе БП (200 мка). При этом более сильным ингибитором канцерогенного воздействия ока-

Таблица 1

Влияние фенолов на канцерогенное действие бенз(а)пирена

\begin{tabular}{|c|c|c|c|c|c|c|}
\hline \multirow{2}{*}{ Серия } & \multirow{2}{*}{$\begin{array}{c}\text { Условия } \\
\text { аппликации }\end{array}$} & \multirow{2}{*}{ Вещества } & \multicolumn{2}{|c|}{$\begin{array}{c}\text { Суммарная доза, } \\
10^{-5} 2 \cdot \text { моль }\end{array}$} & \multicolumn{2}{|c|}{$\begin{array}{l}\text { Количество } \\
\text { опухолей, \% }\end{array}$} \\
\hline & & & БП & $\Phi$ & $\begin{array}{l}8 \text { меся- } \\
\text { цев }\end{array}$ & $\begin{array}{l}12 \text { меся- } \\
\text { цев }\end{array}$ \\
\hline I & Раздельно & $\begin{array}{l}\text { БП-I } \\
\text { БП-II } \\
\Phi \\
M P\end{array}$ & $\begin{array}{l}0,08 \\
0,17 \\
-\end{array}$ & $\begin{array}{l}\overline{-} \\
6,2 \\
6,0\end{array}$ & $\begin{array}{c}3,3 \\
57,9 \\
0 \\
0\end{array}$ & $\begin{array}{r}15,1 \\
100,0 \\
5,3 \\
0\end{array}$ \\
\hline II & Совместно & 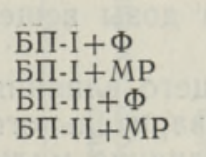 & $\begin{array}{l}0,08 \\
0,08 \\
0,17 \\
0,17\end{array}$ & $\begin{array}{l}6,2 \\
6,0 \\
6,2 \\
6,0\end{array}$ & $\begin{array}{c}5,3 \\
0 \\
50,0 \\
35,0\end{array}$ & $\begin{array}{c}5,3 \\
0 \\
94,4 \\
95,0\end{array}$ \\
\hline III & Последовательно & $\begin{array}{l}\text { БП-I+Ф } \\
\text { БП-I+MP }\end{array}$ & $\begin{array}{l}0,08 \\
0,08\end{array}$ & $\begin{array}{l}6,2 \\
6,0\end{array}$ & $\begin{array}{l}10,5 \\
26,3\end{array}$ & $\begin{array}{l}47,4 \\
57,9\end{array}$ \\
\hline
\end{tabular}

Пр и м ч а и е: БП-I доза 200 мка на мышь, БП-II доза 435 мкट на мышь. 
зался МР. Иная зависимость наблюдается при последовательной аппликации (серия III) БП и фенолов, которые в этом случае действуют как коканцерогенные агенты, промотируя воздействие БП. МР при этом вновь играет роль более активного агента по сравнению с Ф. Следует отметить, что наиболее ярко это проявляется в начальном периоде, а с течением времени и увеличением количества опухолей разница между группами несколько сглаживается.

Попытаемся рассмотреть более подробно явление ингибирования фенолами канцерогенного воздействия БП при их совместном нанесении,

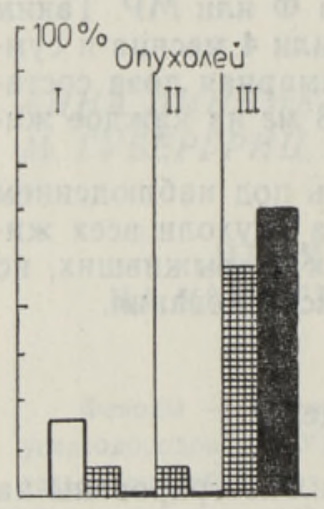

Бенз(а)пирен

曲 Фенол

5-Memunрезориин имея в виду физико-химические закономерности окислительной деградации вводимых химических агентов. С этой целью нами вводится некоторый критерий оценки ингибирующего воздействия. Он определяется отношением аддитивной суммы опухолей, вызванных раздельным действием БП и фенолов, к числу злокачественных новообразований, возникших при совместном действии БП и соответствующего фенола. В табл. 2 наряду с приведенными данными для обеих серий эксперимента с сопряженной аппликацией БП и фенолов включены показатели эффекта ингибирования процессов окисления этими фенолами в других системах $\left[{ }^{13}, 14\right]$,

Влияние фенола и 5-метилрезорцина на образование опухолей кожи у мышей при раздельном (I), совместном (II) и последовательном (III) нанесении.

Эти данные вновь убедительно свидетельствуют о повышенной ингибиторной способности МР по сравнению с Ф относительно БП, причем это свойство проявляется в большей или меньшей мере не только в данном эксперименте, но и при фотохимическом $\left.{ }^{14}\right]$ или метаболическом окислении БП в присутствии фенолов на коже мышей $\left[{ }^{13}\right]$. Для сравнения сошлемся на результаты нашей обработки [15] данных по антиокислительной способности фенолов разного строения применительно к модельной резкции - ингибированию процесса окисления этиллинолеата $\left[{ }^{16}\right]$. Если приблизительная величина константы скорости окисления $k_{7} \cdot 10^{-1}$ для Ф равна 16 , то для МР она составляет 32 , а для хорошо известного антиокислителя - ионола (2,6-дитретбутил, 4-метилфенол) равна 600. Дополнительно сошлемся на данные работы $\left[{ }^{17}\right]$, которые изменение ингибирующей способности фенолов в процессе биохимического окисления их смесей характеризуют следующим образом: $M P>\Phi>$ остальные фенолы.

Таким образом, во всех рассмотренных окислительных процессах, независимо от сложности изучаемой системы, ингибирующее воздействие фенолов определяется исключительно особенностями их структуры и связанной с ней реакционной способностью соединения при условии строгого соблюдения постоянства дозы вещества и времени его воздействия.

Что же касается промотирующего влияния фенолов при последовательном их нанесении (после предварительного воздействия БП), то приведем данные [ $\left.{ }^{9}\right]$ о направлении влияния малых доз ионола на канцерогенное воздействие БП на различных стадиях процесса. В начальном периоде, когда антиокислительная активность (АОА) липидов уменьшается, ионол служит ингибитором канцерогенеза (степень ингибирова- 

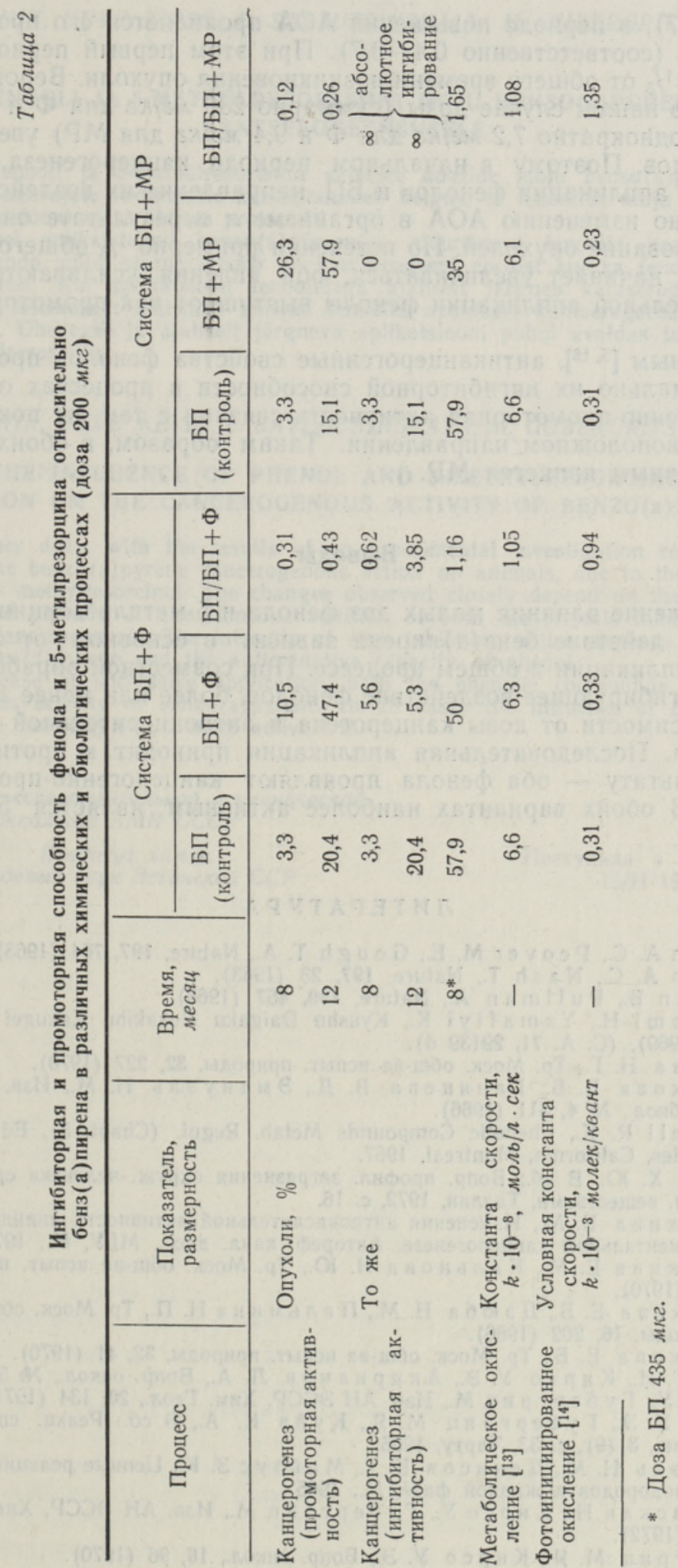
ния $2,3-2,7)$, в периоде повышения $\mathrm{AOA}$ проявляется его промоторная активность (соответственно 0,4-0,7). При этом первый период составляет около $1 / 3$ от общего времени возникновения опухоли. Вероятно, применяемые в нашем случае дозы (суммарно 230 мг/кг для Ф и 300 мг/кг для $\mathrm{MP}$ и однократно 7,2 мг/ке для $Ф$ и 9,4 мг/ке для $\mathrm{MP)}$ увеличивают AOA липидов. Поэтому в начальном периоде канцерогенеза, т. е. при совместной аппликации фенолов и БП, направление их воздействия противоположно изменению $\mathrm{AOA}$ в организме и в результате они ингибируют образование опухолей. По истечении примерно $1 \frac{1}{3}$ общего времени, когда AOA начинает увеличиваться, оба явления усиливаются и при последовательной аппликации фенолы выступают как промоторы канцерогенеза.

По данным $\left[{ }^{5,18}\right]$, антиканцерогенные свойства фенолов проявляются пропорционально их ингибиторной способности в процессах окисления, а канцерогенно-промоторная активность связана с тем же показателем, но в противоположном направлении. Таким образом, в обоих случаях более активным является MP.

\section{Выводы}

Направление влияния малых доз фенола и 5-метилрезорцина на канцерогенное действие бенз(а)пирена зависит в основном от способа и времени аппликации в общем процессе. При совместной обработке установлено ингибирующее воздействие фенолов, более или менее значительное в зависимости от дозы канцерогена и антиокислительной способности фенола. Последовательная аппликация приводит к противоположному результату - оба фенола проявляют канцерогенно-промоторные свойства. В обоих вариантах наиболее активным является 5-метилрезорцин,

\section{ЛИТЕ РАТ У РА}

1. A11 is on A. C., Peover M. E., Gough T. A., Nature, 197, 764 (1963).

2. Allis on A. C., N a sh T., Nature, 197, 23 (1963).

3. Pullm a n B., Pullm a n A., Nature, 199, 467 (1963).

4. Murakami H., Y a ma f i i K., Kyushu Daigaku Nokakibu Kakugei Zasshi, 24, 19 (1969), (C. A. 71, 29139 d).

5. Х р а п о в а Н. Г., Тр. Моск. общ-ва испыт. природы, 32, 227 (1970).

6. Бурлакова Е. Б., Гаинцева В. Д., Эмануэль Н. М., Изв. АН СССР, сер. биол., № 4, 511 (1966).

7. B outwell R. K., Phenolic Compounds Metab. Regul. (Chapt. 5), Ed. Finkle, A. Runcles, California, Montreal, 1967.

8. М и р ме Х. Ю., В сб.: Вопр. профил. загрязнения окруж. человека среды канцероген. веществами, Таллин, 1972, с. 16.

9. Молоч.кин а Е. М., Изменения антиокислительной активности липидов при экспериментальном канцерогенезе. Автореф. канд. дисс., МГУ, М., 1971.

10. Молочкина Е. М., Кальнов а Н. Ю., Тр. Моск. общ-ва испыт, природы, 32 , $173(1970)$.

11. Бурл аков а Е. Б., Д $о$ ю а Н. М., П альмин а Н. П., Тр. Моск. общ-ва испыт. природы, 16, 202 (1966).

12. Бу у лаков а Е. Б., Тр. Моск. общ-ва испыт. природы, 32, 41 (1970).

13. К ар у Т. И., К и рсо У. Э., Андри анов Л. А., Вопр. онкол., № 5, 80 (1973).

14. К и р с о У., Г у бе р г р и М., Изв. АН ЭССР. Хим. Геол., 20, 134 (1971).

15. К и рсо У. Э., Г убе ргриц М. Я., К уй в К. А., В сб.: Реакц. способн. орг. соедин., 3 (9), с. 33, Тарту, 1966.

16. Э м а н уэль Н. М., Д ен и сов Е. Т., М а й з ус 3. К., Цепные реакции окисления углеводородов в жидкой фазе, М., 1965.

17. Берновская Н., К ирсо У., Губергриц М., Изв. АН ЭССР, Хим. Геол., 21, 116 (1972).

18. Г у бергрищ М. Я., Кирсо У. Э., Вопр. онкол., 16, 96 (1970). 
ANNA LINNIK, UUVE KIRSO, L. SAVLUTSINSKAJA, M. GUBERGRITS, L. SABAD

\section{FENOOLI JA 5-METUULRESORTSIINI MOJU BENSO(a)PUREENI KANTSEROGEENSUSELE}

Uuriti fenooli ja 5-metüülresortsiini väikeste dooside mõju benso(a)püreeni poolt pōhjustatud kasvajate tekkimisele katseloomadel. Selgus, et fenoolide mōju suund sōltub nende aplikatsiooni ajast üldises protsessis.

Oheaegsel aplikatsioonil benso(a)püreeniga pidurdavad fenoolid kasvajate teket, kusjuures nende môju suurus oleneb nii kantserogeeni doosist kui ka fenooli antioksüdeerimisvõimest. Kui aplikatsioon fenoolidega ajaliselt järgneb kantserogeenile, saadi vastupidised tulemused: mōlemad uuritud fenoolid avaldasid kantserogeenset-promootorlikku toimet. Oheaegse ja ajaliselt järgneva aplikatsiooni puhul avaldas tugevamat toimet 5-metüülresortsiin.

ANNA LINNIK, UUVE KIRSO, L. SAVLUCHINSKAYA, M. GUBERGRITS, L. SHABAD

\section{THE INFLUENCE OF PHENOL AND 5-METHYLRESORCINOL ADDITION ON THE CANCEROGENOUS ACTIVITY OF BENZO(a)PYRENE}

The paper deals with the results of an experimental investigation concerning the change in the benzo(a)pyrene cancerogenous action on animals, due to the addition of phenol or 5- methylresorcinol. The changes observed closely depend on the time of the application of phenols. A simultaneous addition of both the phenols inhibits the total process of cancerogenesis. The intensity of such inhibiting action depends on the total dose of benzo(a)pyrene and the antioxidative capacity of phenol.

In the case of successive application, both the phenolic compounds promote the cancerogenous activity of benzo(a)pyrene. In all cases the influence of 5-methylresorcinol may be considered as a more active one.

Институт экспериментальной и клинической онкологии АМН СССР

Институт химии

Академии наук Эстонской ССР
Поступила в редакцию 16/II 1973 